\title{
Spatial targeting and prediction of factors responsible for optimum Covid-19 based social distancing - the case of Upper west region, Ghana
}

Moses Asori ( $\square$ asorimoses00@gmail.com )

Kwame Nkrumah University of Science and Technology

\section{Ali Musah}

Kwame Nkrumah University of Science and Technology https://orcid.org/0000-0002-1438-4020

Prince Peprah

University of New South Wales

\section{Research Article}

Keywords: Covid-19, ease of social distancing index, hotspots, geographically weighted regression

Posted Date: February 17th, 2022

DOl: https://doi.org/10.21203/rs.3.rs-1364371/v1

License: (c) (i) This work is licensed under a Creative Commons Attribution 4.0 International License.

Read Full License 


\title{
Spatial targeting and prediction of factors responsible for optimum Covid-19 based social distancing - the case of Upper west region, Ghana
}

\begin{abstract}
Covid-19 has become a significant global public health concern due to its faster rate of mortality and morbidities. Various precautionary measures such as social distancing have been outlined across the globe to reduce its transmission. However, the practicality of implementing the social distancing is a function of multiple factors including; urban morphology, population density and availability of essential socioeconomic services. Using Getis-Ord G* and Spatial-Cluster outlier analysis, we targeted the hotspot centres where effective social distancing will be difficult to achieve within Upper West Region in order to optimize intervention and resource allocation. We also examined factors determining effective Social Distancing using Geographically Weighted Regression (GWR). Ease of achieving social distancing index (ESDI) was acquired from WorldPop Group Research centre at Southampton University, Freshwater availability from Socioeconomic Data and Applications Center (SEDAC) and Average household size from DHIMS-2. Our spatial statistical analysis indicates that ESDI is significantly spatially auto-correlated; with hotspots occurring generally at the urban core. Using both the global (OLS) and local (GWR) regression models, we found that, relationships between ESDI and built-up area, built-up proportion, population density and freshwater availability were statistically significant. We suggest that areas where it is difficult to achieve social distancing due to built-up design or population density, constant surveillance should be adopted for timely detection.
\end{abstract}

Keywords: Covid-19; ease of social distancing index; hotspots; geographically weighted regression

\subsection{Introduction}

Globally, covid-19 has disrupted various socio-economic aspects of our lives, including crippling the economies of many countries (Ferguson et al., 2020; Appiah-Otoo \& Kursah, 2021; Nasiri et al., 2021). The first Covid-19 confirmed case was reported from Wuhan, China around November 2019 (Yeboah et al., 2020). Since its reportage from Wuhan, China, its transmission has been extremely faster due to human-to-human interaction and the greater frequency of physical contact (Richardson et al., 2021). As of $16^{\text {th }}$ February, 2022 there was 414 million confirmed cases and 5.83 million deaths globally (worldometers, 2022). With recent surge in the Omicron variant, the transmission rate and infection has increased tremendously. As a result, it has impacted significantly on both the ingoing and planned socioeconomic events. It has affected the accessibility to schools and access to water, hospitals and businesses in various countries including Ghana (Affran et al., 2020; Upoalkpajor \& Upoalkpajor, 2020).

A social accounting matrix multiplier modelling indicated that during the first three months in the lockdown period, Ghana's GDP decreased by $27 \%$ where 3.8 million people became temporary unemployed (Amewu et al., 2020). The impact of the covid-19 on Ghana's healthcare systems and public health broadly, is even far reaching (Asante et al., 2021). Even though, since the beginning of the year 2021, a number of vaccines have been developed and distributed globally of which Ghana has been a noticeable beneficiary of these vaccines; the spread of the virus is still conspicuous in the country as over 100s of new cases are recorded daily (worldometers.info/coronavirus/). The situation has even been aggravated by the 
discovery of the omicron variant of the virus. In an attempt to manage and attenuate the spread of the Covid-19 virus, a number of measures have been operationalized (Pfattheicher, Nockur, B€ohm, Sassenrath, \& Petersen, 2020; Prem et al., 2020). Among these measures, physical/social distancing is seen as one of the most certain ways of preventing the spread of the virus. Some experts have observed that almost $90 \%$ of the spread can be curtailed through physical and social distancing practices (Lewnard \& Lo, 2020; Park, Sun, Viboud, Grenfell, \& Dushoff, 2020). Given these recommendations, it has become crucial that social distancing be firmly integrated into public health policies; as we still try to contain the virus. On the bases that the spatial, social and economic circumstances will jointly act to determine the effectiveness of social/physical distancing as appropriate strategy to reducing the spread of the Covid-19 (Durizzo et al., 2021; Morgan, 2020; Yeboah et al., 2020), most places in Ghana including Wa are experiencing implementation difficulties. Though a few number of studies have investigated the practicality of implementing social distancing in urban centres in Africa (Katey et al., 2021; Morgan, 2020; Yeboah et al., 2020), the focus has largely centred on social and economic dimensions with almost none-concentrating on the spatial and physical aspect. Typically most urban poor live in small parcels of lands -which favours overcrowding and transmission of contagious and communicable diseases (Adelekan, 2010; Baker, 2012; Delhi, 2003). Some researchers (Durizzo et al., 2021; Morgan, 2020; Yeboah et al., 2020) argue that the effectiveness of the SD implementation will partly depend on human willingness to abide by the rules set out, and the effectiveness of policies controlling people compliance to the operationalized measures.

It is also reasonable to argue that in some urban spaces where overcrowding is common in terms of population and built-up footprints, implementing SD will be practically difficult to achieve - in its blunt state. As instance, in many communities in Ghana and in Upper West especially, many houses do not have access to toilet facilities and water; and are therefore compelled to be in queue in order to access these services (Braimah \& Filmua, 2011; Fielmua et al., 2019). So even if they are willing to practice the SD measures outlined by the WHO, the nature of their social and spatial design may militate against their "good will". Thus elevating their exposure and risk levels to the virus. For example, a study conducted in Accra and Johannesburg in 2021, involving 1,400 respondents found that though many of the urban poor in Accra and Johannesburg observed appropriate hygienic attitude and generally, the willingness to follow social distancing rules. However, despite the city-wide lockdown in these cities many people still defaulted in abiding by the social distancing rules.

Approximately 25-30\% of people reported attending larger social gathering, $10-20 \%$ reported receiving guests at homes and $30-35 \%$ of the people leave their homes more than once per week (Durizzo et al., 2021). Further investigation revealed that their inability to abide by the social distancing rules was related to lack of infrastructure such as basic social services (water and sanitation services), and poverty but not the mere unwillingness of the people to accept the new behavioural change enshrined in the social distancing guidelines (Durizzo et al., 2021). As a result, different or modified SD measures may be needed in these communities where blunt SD measures may be extremely difficult.

Currently, in Upper West, there is no study investigating the hotspots location of where social distancing will be difficult as well as spatial predictors of the ease of achieving SD. It is worth mentioning that, almost all studies on covid-19; from impact to transmission dynamics, have focused on the two largest Ghanaian cities -Kumasi and Accra (Affran et al., 2020; L. 
A. Asante \& Mills, 2020; Durizzo et al., 2021; Morgan, 2020); as such there is policy bias in managing the virus in the country. Even though, relatively, Upper West region has few recorded cases (895) as of $16^{\text {th }}$ February 2022 (worldometers.info/coronavirus/; https:/www.ghs.gov.gh/covid19/dashboardm.php ), it is one of the socioeconomically unique region characterised by severe poverty (arguably the poorest region in Ghana) and lack of access to sanitation, water and healthcare facilities (Baada et al., 2021); at the same time, UWR is one of the hotpot regions of meningitis outbreaks in the country, further crippling their healthcare systems (Akyereko et al., 2020; Nuoh et al., 2016). GSS (2013; 2015) cited in Baada et al. (2021) estimated that $70.7 \%$ of people in UWR were poor, which is higher than the national average of $30.9 \%$. Therefore the brunt of covid- 19 will arguably have the greatest impact on the people. However, spatially monitoring the hotspots locations within the region where SD will be difficult is currently lacking. Given the varying nature of socioeconomic and physical circumstances (Amewu et al., 2020; Durizzo et al., 2021), spatially pointing exactly where SD will be difficult, and predictors of the difficulty is crucial to developing spatially targetable policies for modifying or finding alternative -but effective measure of limiting the spread. We presumed that, places with higher proportion of buildings, higher population density and greater built-up footprint area will increase the propensity of social interaction and physical contact (which is a podium for the virus transmission). We also presumed that, since water is inevitable consumable, places with less freshwater supply, the probability of people queuing for public water accessibility will be higher, and will therefore increase physical contact and social interaction. The integrated effects of these factors were presumed to determine whether physical distancing will be practicable or not. This study therefore seeks to apply savvy geospatial techniques to map hotspots areas where it is very difficult to achieve social distancing and physical and spatial predictors of the easiness SD to help also give policy focus to such an economically deprived region in the country

\subsection{Materials and methods}

UWR, located in the north-western part of Ghana is one of the 16 administrative regions of Ghana, and it's situated in the Guinea/Sudan-Savannah vegetation zone with about $84 \%$ rural population; the highest in the country and closer to a double of national average of 49.1 . 


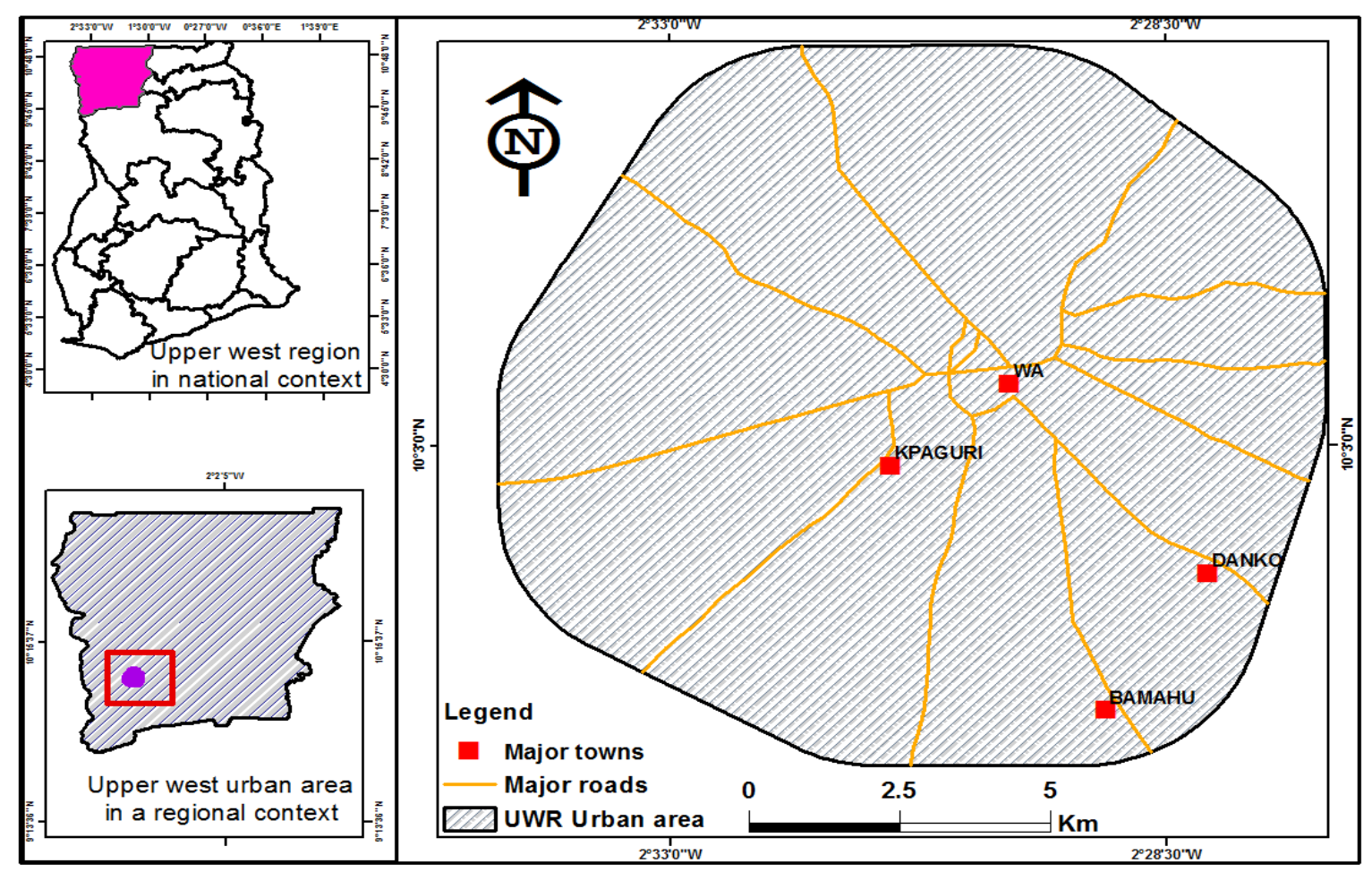

Figure 1: Study area map

Geographically, it is boarded by upper east region to the east, to the south by Ahafo and Brong regions and North by Burkina-Faso. According to GSS $(2013 ; 2015)$ cited in Baada et al. (2021) estimated that $70.7 \%$ of people in UWR were poor, which is higher than the national average of $30.9 \%$. It is therefore one of the socioeconomically unique region characterised by severe poverty (arguably the poorest region in Ghana) and lack of access to sanitation, water and healthcare facilities (Baada et al., 2021); at the same time, UWR is one of the hotpot regions of meningitis outbreaks in the country, further crippling their healthcare systems (Akyereko et al., 2020; Nuoh et al., 2016). Even though, relatively, Upper West region has few recorded cases (895) as of $16^{\text {th }}$ February 2022, due to its socio-economically vulnerable nature, the brunt of covid-19 will arguably have the greatest impact on the people, also practicing the SD measures will be practically difficult. Against this backdrop that, we sought to investigate social distancing condition to scale-up intervention in this region's urban space. The study aimed to map hotspots areas where achieving social distancing is relatively difficult using several spatial clustering techniques; and how that is predicted by (1) population density, (2) spaces around building, (3) household size and (4) freshwater availability within Upper west region.

\subsection{Datasets and sources}

The ease of social distancing index (ESDI) is a composite measure that is based on available spaces around buildings and the estimated population density, which is available in 50 countries (release@worldpop.org). The index and derived values were calculated for smaller spatial units (polygon vectors) typically bounded by roads, rivers or other spatial features. The population density was calculated from high resolution population data sets extracted from WorldPop, and spaces around building computed from building footprint using high resolution satellite imagery (Ecopia.AI and Maxar Technologies, 2020). The ESDI was 
produced by WorldPop Research group at the Southampton University, which is funded by Bill and Melinda Gates Foundation and the United Kingdom's Foreign, Commonwealth \& Development Office (INV-009579, formerly OPP1182425), and GRID3 COVID-19 Support Scale-up (INV-018067). The project partners involved the United Nations Population Fund (UNFPA), Center for International Earth Science Information Network in the Earth Institute at Columbia University, and the Flowminder Foundation. For detailed method development, geospatial data processing, coding and dataset production consult (release@worldpop.org) or Chamberlain et al (2021). The datasets included the following fields.

- UNIT_AREA: The area of the spatial unit (polygon) in metres squared, computed in the relevant UTM zone projection.

- BUILT_AREA: The added area of all building footprint polygons within the spatial unit. Units are metres squared. So literally how large or small the building footprint is.

- BUILT_PROP: The proportion of the spatial unit that is built, calculated as BUILT_AREA/UNIT_AREA.

- NBUILTPROP: The proportion of the spatial unit that is not built, calculated as 1BUILT_PROP.

- POP_DENS: The average population density (population per $\mathrm{km}^{2}$ ) of the vector polygon (the spatial unit), computed for all the grid cells that have their centroids within the spatial unit.

- BUILTscore: Built score (0-10), classified based on the BUILTPROP field. A value of 10 means $90 \%$ of the unit area is occupied by buildings and a value of 1 corresponding to less than $10 \%$ of the unit area made of buildings, but with at least 1 building present. A value of 0 indicates a spatial unit with no buildings.

- POPscore: Population density score (0-10), classified based on the POP_DENS field, with a value of 1 representing low population density and a value of 10 indicating very high population density. A value of 0 indicates a spatial unit with average population density of 0 people per $\mathrm{km}^{2}$. A no data value (-99) indicates missing data.

- INDEXvalue: Ease of social distancing index value (0-10), computed as average of the BUILTscore and POPscore field figures. A value of 1 is suggestive of relative ease of social distancing due to low population density and enough space around buildings. A value of 10 is indicative of high difficulty in maintaining social distancing due to very high population density and very little space around buildings. A no data value (-99) indicates missing data.

For full data sources used in developing this composite datasets, kindly see (release@worldpop.org) and Chamberlain et al (2021). Data related to availability of fresh water availability was obtained from SEDAC (https://sedac.ciesin.columbia.edu/data/set/sdeitrends-freshwater-availability-grace/data-download). The terrestrial water availability measures the rate of freshwater change (in centimetres per year) from 2006 and 2016 which is used for spatial monitoring of hotspots areas of water unavailability which can affect accessibility; in both urban and rural areas (Rodell et al., 2019). This data is produced through Gravity Recovery and Climate Experiment (GRACE) method led by NASA, which is available for the entire world at 0.5 degree resolution. We clipped this datasets to our current study spatial scope in GIS environment. We also acquired data on the size of household size at a sub-district level from GHS database. Since other explanatory and response variables were in a spatial unit of the ESDI, we transform our household to fit into 
these micro-vector polygons. We achieved this by first interpolating the values at a subdistrict level using Kriging interpolation method. After, we utilised zonal statistics to fit individual pixel values into the smaller-scaled polygons.

\subsection{Spatial autocorrelation (Global Moran's I)}

Spatial autocorrelation has been a useful technique for assessing the degree to which similar values - of specific phenomenon tend to cluster together in space. Essentially, the Morans index is a coefficient that measures how similar values lie close to each other. If values are spatially dissimilar to each other, then these values are spatially not dependent, and may therefore be less likely to form a cluster. The Moran's Index is similar to Karl Pearson coefficient (Tsai et al., 2009) which is expressed as;

$$
M I=\frac{N}{S_{\alpha}} \sum_{I} W_{I K} \sum_{K} W_{I K} \frac{\left(Y_{i}-P\right)\left(Y_{K}-P\right)}{\left.\sum_{I}\left(Y_{I}-P\right)^{2}\right)}
$$

Where MI is the Global Moran's I statistics, $\mathrm{N}$ is the Number of spatial polygons containing our attribute of interest considered in our study; $S_{\alpha}$ and is the spatial attribute, which is further defined as:

$$
S_{\alpha}=\sum_{I} W_{I K} \sum_{K} W_{I K}
$$

Where $W_{I K}$ is the element in the spatial weight which is equal to the observation pair; I, $\mathrm{K}$ and YK for locations I and $\mathrm{K}$ with average field value $\mathrm{y}$. Typically an addition of all the spatial weights must be equal to 1 , which is defined as $\left(\sum_{I} W_{I K} \sum_{K} W_{I K}=1\right)$, and usually, the weights are constructed per evidence of neighbouring locational values based on an ideal bandwidth; all values beyond this bandwidth which defines a neighbourhood is indicated as having insignificant local influence. For an ideal search radius, we conducted an incremental spatial autocorrelation to determine an optimum distance to use to define our neighbourhood radius. The third peak which defines a saturation point was used for our study. Results of our incremental spatial autocorrelation is presented in Table 1

Table 1: Results of incremental spatial autocorrelation

\begin{tabular}{llll}
\hline Incremental Distance $(\mathrm{m})$ & Morans Index & Z-score & $\mathrm{p}$-value \\
\hline 1483 & 0.38 & 85.82 & $\mathrm{P}<0.001$ \\
1650 & 0.36 & 89.15 & $\mathrm{P}<0.001$ \\
1817 & 0.33 & 90.22 & $\mathrm{P}<0.001$ \\
1984 & 0.29 & 91.05 & $\mathrm{P}<0.001$ \\
2152 & 0.27 & 91.01 & $\mathrm{P}<0.001$ \\
2319 & 0.25 & 89.69 & $\mathrm{P}<0.001$ \\
2486 & 0.22 & 87.74 & $\mathrm{P}<0.001$ \\
2653 & 0.21 & 86.13 & $\mathrm{P}<0.001$ \\
2821 & 0.17 & 83.37 & $\mathrm{P}<0.01$ \\
2988 & 0.16 & 80.14 & $\mathrm{P}<0.01$ \\
\hline
\end{tabular}

$\mathrm{P}<0.001^{*}$ (all p-values were significant at 0.05 )

The spatial autocorrelation analysis usually result in five statistical indices (Moran's I, expected index, variance, z-score and p-value). Moran's index ranges between 1 and -1; 
where positive values is indicative of clustering and negative values indicating dispersal of phenomenon of interest; and in our study, social distancing easiness index

\subsection{Spatial cluster outlier analysis (local Morans index)}

Typically, the global Moran's index measures the propensity of clustering or dispersion of similar or dissimilar values, but does not reveal the true local autocorrelation of the phenomenon. The cluster outlier measures how statistically significant $(\mathrm{p}>0.01)$ or insignificant $(p<0.01)$ low values lie close to low values (Low-Low), higher values lie closer to higher values (High-High) or low to high and vice versa. In this study we assessed the tendency of social distancing index with higher values lying closer to lower figures (HighLow); higher to high (High-High); high to low (High-Low) and low to high (Low-High) at a significance level of 0.05 . Anselin Local Moran's I was utilized to observe the spatial outlier in our variable of key interest (SD index). A positive index indicates values of similar degree lying closer to each other; whereas negative index shows values enclosed with dissimilar values. We interpreted the nature of the local spatial autocorrelation based on $\mathrm{z}$-score and $\mathrm{p}$ value where a $p$-value of 0.05 was chosen as our significant determiner of strong autocorrelation of our spatial variables.

\subsection{A hotspot and coldspot analysis (Getis-Ord Gi* statistics)}

A hotspot refers to a region or a spatial unit which has higher saturation of events relative to expected random distribution. Even though hotspot/cluster analysis is quite similar to density analysis, the hotspot technique has means of determining how significant the concentration of similar values are. Generally there are two outcomes; hotspot and cold pots which are explained by the z-score and p-values. A higher z-score and low p-value indicates places of higher concentration of higher values whereas negative z-score and low p-values show places where low values are concentrated together. In our study, we used Getis-Ord analysis to differentiate places of hotspots (vulnerable areas) from areas of coldspots (non-vulnerable areas). The model is specified as;

$$
G=\frac{\sum_{i=1}^{n} W_{i, k, y k}-Y_{b a r} \sum_{i=1}^{n} W_{i, k}}{\sqrt[s]{\frac{n \sum_{i=1}^{n} W^{\wedge} 2_{i, k}-\left(\sum_{i=1}^{n} W_{i, k}\right)^{\wedge} 2}{n-1}}}
$$

Where $y k$ is the attribute value of the event $\mathrm{k} ; W_{i, k}$ is the spatial weight of 1 and $\mathrm{k}, \mathrm{n}$ is the total number of features or events, and;

$$
\bar{X}=\sum_{K=1}^{n} y_{k}
$$

And;

$$
\mathrm{S}=\sqrt{\frac{\sum_{K=1}^{N} y_{k}^{2}}{n}}-X_{b a r}^{2}
$$

The result expresses the high z-score and low $\mathrm{p}$ value of computed $G_{i}^{*}$ which represent the statistical significance of spatial clusters. In the present study, $G_{i}^{*}$ was used to identify the vulnerable and non-vulnerable zones indicating hotspot (spatial clusters of high values) and cold spots (spatial clusters of low values) respectively.

\subsection{Modelling spatial relationships}


Though a number of models exist for evaluating relationships that occur between variables including the well-known ordinary least squares (OLS), they lack spatial significance. Most of these non-spatial statistical models assume that relationships between variables are constant in space (Brunsdon, Fotheringham, \& Charlton, 1996; Fotheringham, Charlton, \& Brunsdon, 1998), with no explicit variations among relationships within any spatial context. However, as human interactions, physical environmental indicators and built-up design vary even at a micro-scale (Chamberlain et al., 2021), it is essential to relax such stationarity assumption which usually mask true spatial dynamics. In effect, we relied on spatial model that handles the variability of events in space using Geographically Weighted Regression (GWR). Particularly GWR builds a local parameter for each linked variable in a specific location; the model is expressed mathematically as;

$$
y_{i}=\beta_{o i}\left(u_{i}, v_{i}\right)+\sum_{n=1}^{k} \beta_{n i}\left(u_{i}, v_{i}\right) x_{n i}+e_{i}
$$

Where $y_{i}$ represent the response variable (the ease of achieving optimum social distancing index), $\beta_{o i}$ is the spatial variable effect intercept at particular spatial unit $\mathrm{i},\left(u_{i}, v_{i}\right)$ is the coordinate of the smaller vector polygons, $\beta_{n i}$ is the effect estimate of a variable $n$ at location $i, x_{n i}$ is the value of an inth predictor variable $\mathrm{n}$ at a location $\mathrm{i}$, and $e_{i}$ is the spatial random error term associated with the model estimation of relationship effect. Here, our dependent variable was ease of social distancing index (ESDI), where our independent variables were (1) population density, (2) built-up proportion, (3) built-up area $\left(\mathrm{m}^{2}\right)$, (4) freshwater availability and (5) average household size per each smaller spatial unit. The effect parameter modelled for a particular independent variable on the outcome variable at a particular location within our study area is typically given in a matrix form which is expressed mathematically as;

$$
\hat{B}(i)=\left(X^{\prime} W(i) X\right)^{-1} X^{\prime} W(i)
$$

Where $\widehat{\mathrm{B}}$ is the vector of the parameter estimate ( $P \times 1), \mathrm{X}$ shows the matrix of the chosen independent variable $(n \times p)$, W (i) represents the matrix of spatial weights $(n \times n)$ while $y$ indicates the vector observation of the ease of social distancing index $(p \times 1)$. The matrix $W$ (i) is derived from the weights of each spatial unit according to its distance from location $\mathrm{i}$. In the model calibration and parameter estimation, the type of kernel function that determines an optimal bandwidth is necessary (Mansour et al., 2020). Gaussian and bisquare kernel functions have been commonly used (Mansour et al., 2020). Based on these functions, the Tobler's first law of geography was used where closer neighbours to the target variable is influenced more than variables farther away. The bandwidth is selected based on Euclidean distance and specified number of neighbours. In this our study, we chose the adaptive kernel and bandwidth where a particular bandwidth is largely dependent on the distribution of our spatial variable values.

Before running the model we did exploratory data analysis (EDA) to evaluate the appropriateness of the variables for the model including the degree of multi-collinearity among the predictor variables; which might introduce redundancy into our model. We used the variable inflation factor (VIF) to examine multi-collinearity, uncorrelated variables were then selected for the model. To demonstrate how potential spatial interaction occur between spatial units or polygons, we developed a spatial weight matrix based on first order Queens' contiguity which indicates whether or not spatial units share boundary. According to Wang et 
al. (2020) the significance of spatial weight matrix is to represent the nature of spatial unit and measure the spatial relationships between them.

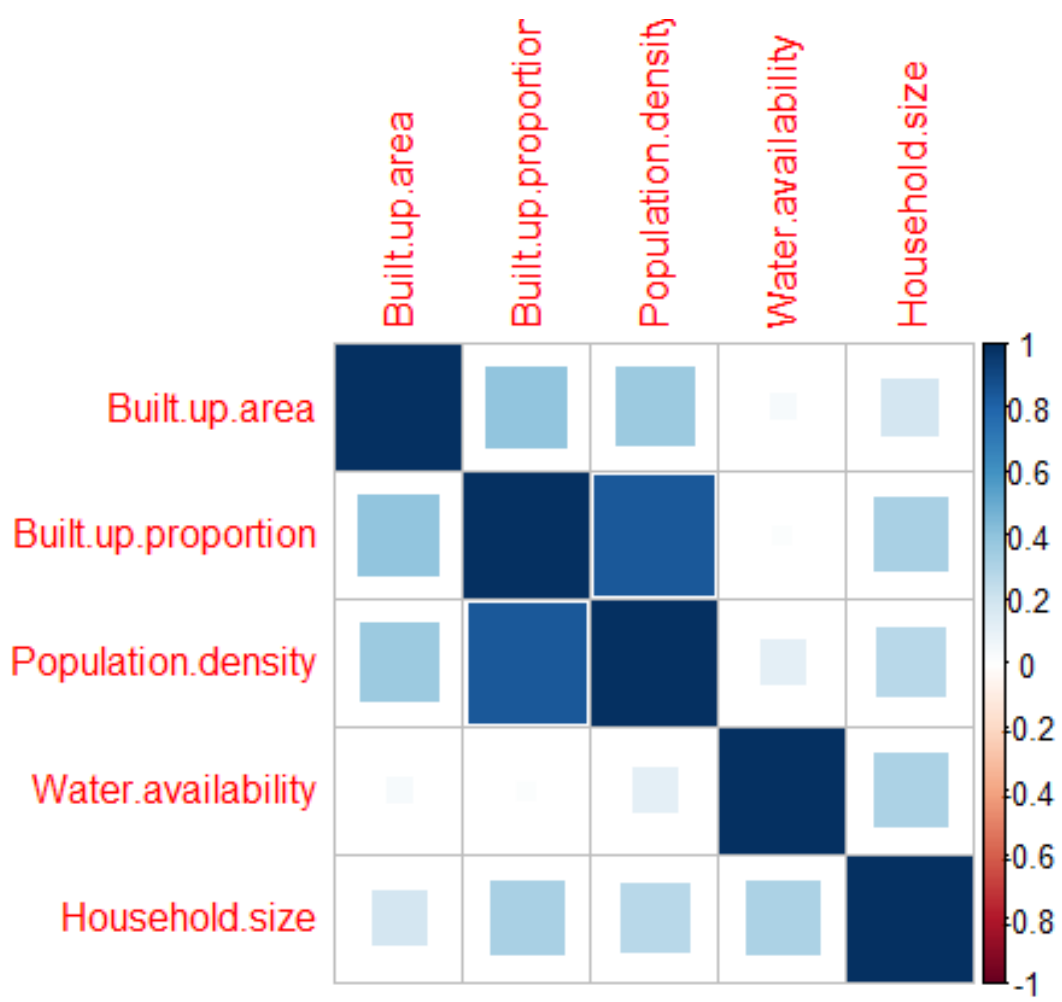

Figure 2: Correlation between the predictors

This weight is inevitable especially since GWR is a local model and thus spatial autocorrelation is an inherent component. To evaluate the goodness of fit of the model, we used corrected akaike information criterion (AICc), and all coefficients of determination was reported in Pearson $r^{2}$ where higher $r^{2}$ and smaller AICc indicated best fit of the model.

\subsection{Findings}

The hotspots and cluster mapping of the ease of achieving social distancing was fitted in microscale spatial units; a vector polygon generated by WorldPop Research group (WRG) bounded by features such as roads, buildings, rivers and other spatial structures. Even though covid-19 vaccination is ongoing in Ghana, access to the vaccine is difficult to the poor due to inequality; thus exposing the vulnerable groups such as the urban poor to the virus. People are advised by the Government of Ghana and Ghana Health Service (GHS) to maintain physical distancing of 6 feet or 2 meters. Nevertheless, the effectiveness of achieving this social distancing protocol may be based on (1) population density (2) intra-urban morphology and (3) access to social and economic services. Our presumption is that, areas where these 


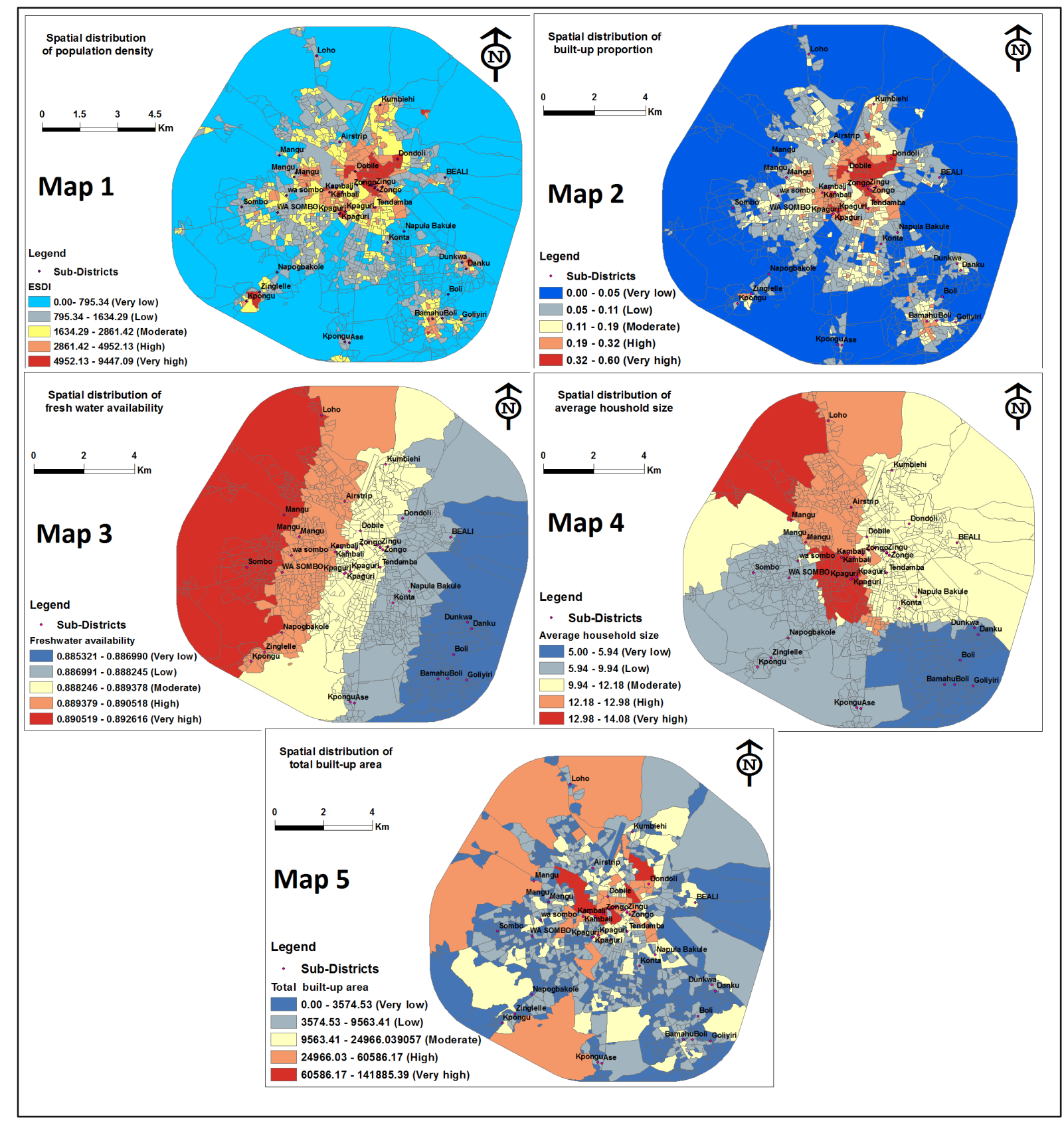

Figure 3: All five variables; population density (map 1), built-up proportion (map 2), freshwater availability (map 3), average household size (map 4) and total built-up area (map 5) used for examining how achievable social distancing is in Upper west region.

Therefore we maintain that, mapping out areas where social distancing will be practically difficult, and whether or not these factors (population density, physical spaces around building and access to social amenities) empirically determines effectiveness of SD - is imperative to finding alternative measures to prevent the spread of the virus.

Global Morans I statistics reveal that the ESDI is spatially auto-correlated where clustering is statistically significant $(I=0.66$; Z-score $=41.37$ and $\mathrm{p}<0.001)$. Results also show that the central location tends to have the constellation of higher $\mathrm{z}$-scores suggesting that these areas are practically difficult to achieve social or physical distancing. These are 
areas of higher population density. For example areas such as, Dobile, Wa Zongo, Zingu and Domdoli fall within very high population density class with density between 4952.13 and 9447.09 persons per $\mathrm{km}^{2}$, communities such as Tendamba, Kpaguri, Kambali and Mangu fall within the high population density class with density ranging from 2661.42 to 4952.13 persons per $\mathrm{km}^{2}$. Bahamu, Wa-Sombo and Zinglelle fall within the moderate density class (1634.29 to 2861.42 persons per $\mathrm{km}^{2}$ ) whereas the rest of the communities such as Beali, Danku, Goliyiri, Napogba and Loho fall within the low to very population density class of maximum of 1634.29 persons per $\mathrm{km}^{2}$. The nature of the population density strongly predicted physical distancing condition where higher population density areas had more difficulties achieving social or physical distancing. The Getis-Ord $\mathrm{G}^{*}$ statistics revealed that 5 communities (Kamabli, Wa sombo, Wa Zongo, Zingu, Dobile, Kpaguri and Tendamba) had significant hotspots of ESDI suggesting that these communities will face difficulties achieving physical or social distancing at $99 \%$ confidence level.

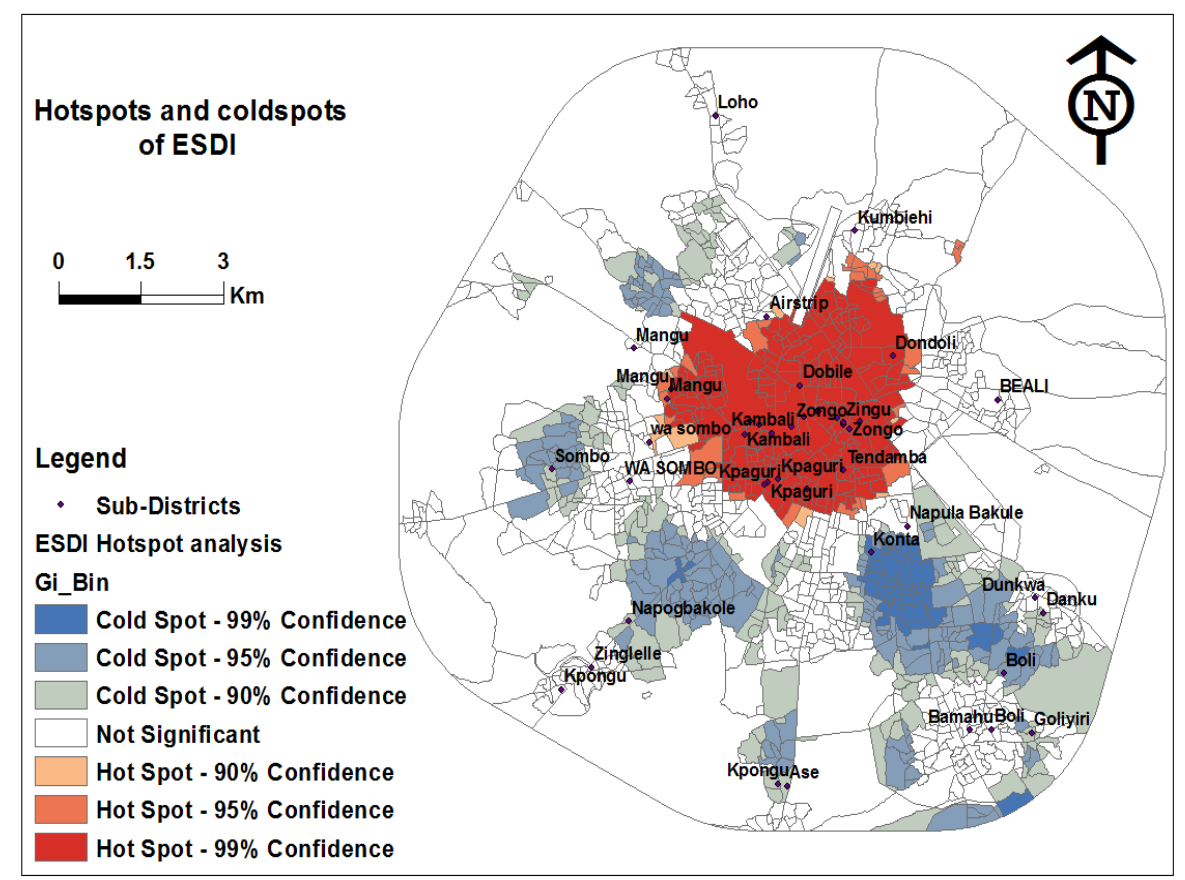

Figure 4: Hotspot analysis of the ease of achieving social distancing index in upper west urban space

Even though Wa-Sombo and Bahamu have moderate population density, they have very significant spatial clustering of higher ESDI. Results also indicate that hotspots of either 95 or $90 \%$ confidence though existed, but very insignificant -in spatial scope (Figure 4). Communities like Konta and Boli lie within coldspots zones at 99\% confidence level. Danku, Dunkwa, Napogpakole, Goliyiri and Sombo lie within coldspots zone at a 95\% and 90\% confidence levels. We further sought to investigate how statistically significant spatial outliers occur in the upper west urban space with respect to ESDI. 


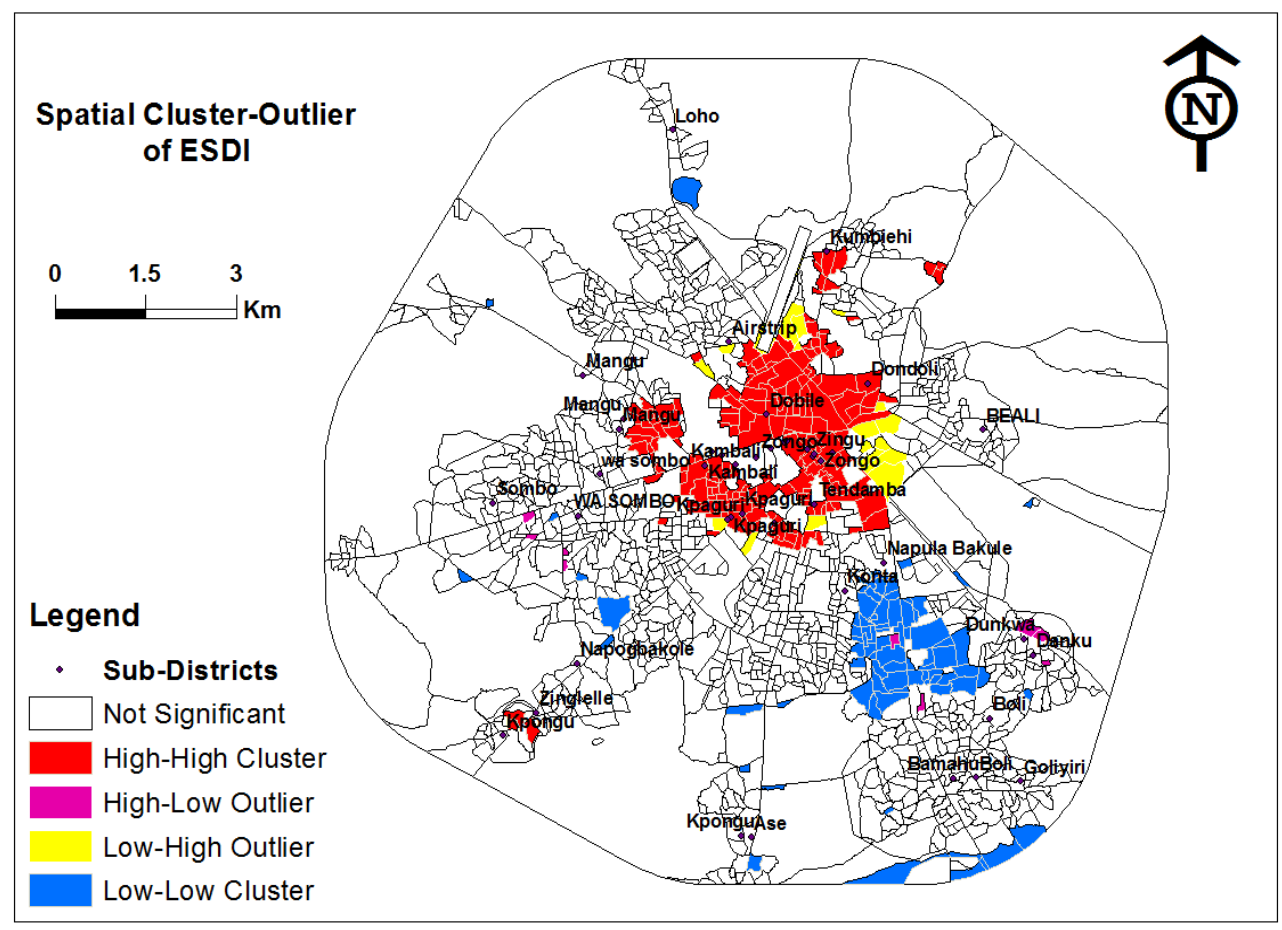

Figure 5: Spatial cluster-Outlier analysis of the ease of achieving social distancing in Upper west urban space

We found 5 Low-Low clusters of ESDI within the urban space, these low-low clusters were found in Konta, Dunkwa, Kponguase, Napogbakole and Loho. We also found High-High cluster within the urban spaces which were found in Zongo, Zingu, Kpaguri, Mangu and Kambali (Figure 5). These are areas where higher values of ESDI are surrounded by higher values (risky zones). We also found 2 significant areas that depicted significant case of spatial outliers where places (including Wa central) with lower values of ESDI positioned closer to places of higher values. Only one place (Danku) displayed a significant spatial outlier scenario where higher values of ESDI positioned closer to places of lower values (High-Low outlier). Similar to the spatial outlier displayed in Wa central, people in Danku are in vulnerable state since they lie close to areas where social distancing is pragmatically difficult to achieve; therefore, through spatial mobility and social interaction, they can easily contract and spread the virus within their neighbourhood as well. About $90 \%$ of the urban space displayed no incidence of local-level spatial autocorrelation or spatial outlier.

To explore the degree and direction of spatially varying relationships between ESDI and built-up proportion, population density, built-up area $\left(\mathrm{m}^{2}\right)$, household size and freshwater availability, we relied on Geographically Weighted Regression (GWR) which builds local parameter estimates for the relationship of interest. All coefficients of determination (except for the relationship between ESDI and freshwater availability) were statistically significant for the global model (OLS).

Table 2: OLS statistics of the relationships between ESDI Built-up area/proportion, population density, household size and freshwater availability.

\begin{tabular}{llllll}
\hline Predictors & $(\mathrm{VIF})$ & $\mathrm{R}^{2}$ & t-statistic & p-value & AICc \\
\hline Intercept & ---- & 0.41 & 31.71 & $0.001^{* * *}$ & -------- \\
Built-up area & 1.19 & 0.16 & 16.06 & $0.003^{* *}$ & 3543.23
\end{tabular}




\begin{tabular}{llllll} 
Built-up proportion & 3.62 & 0.81 & 77.19 & $0.001^{* * *}$ & 1474.72 \\
Population density & 3.58 & 0.84 & 85.35 & $0.001^{* * *}$ & 1245.54 \\
Household seize & 2.23 & 0.01 & 1.14 & 0.253 & 3779.65 \\
Water accessibility & 1.03 & 0.12 & 10.82 & $0.002^{* *}$ & 3667.87 \\
\hline
\end{tabular}

All relationships followed a positive direction. We tested for variable inflation factor (which measures level of redundancy) in our predictor variables. We found no significant multicollinearity in our regressors since no variable had VIF higher than 7.5 as shown in Table 2. The OLS result showed that the relationships between ESDI and built-up area $\left(r^{2}=0.16\right.$; $p=0.003)$, built-up proportion $\left(\mathrm{r}^{2}=0.81 ; \mathrm{p}<0.001\right)$, population density $\left(\mathrm{r}^{2}=0.84 ; p<0.001\right)$ and freshwater availability $\left(\mathrm{r}^{2}=0.12 ; \mathrm{p}=0.002\right)$ were statistically significant, but not average household size $\left(r^{2}=0.012 ; p=0.253\right)$. The local model based on the geographically weighted regression (GWR) showed an improved model performance through a reduced corrected akaike information criterion (AICc) and significant parameter estimates. For example the relationship between ESDI and household size which was insignificant in the global model improved with the local model. For instance, we found improved strength of relationships between ESDI and all predictors; built-up area $\left(r^{2}=0.47\right)$ as compared with $r^{2}$ of 0.16 in the OLS model. We also found improved estimate for built-up proportion $\left(\mathrm{r}^{2}=0.86\right.$ vs $\mathrm{r}^{2}=0.81$ in OLS), population density $\left(\mathrm{r}^{2}=0.89 \mathrm{vs} \mathrm{r}^{2}=0.84\right.$ in OLS $)$, availability of freshwater $\left(\mathrm{r}^{2}=\right.$ 0.96 vs $^{2}=0.12$ in OLS) and household size $\left(r^{2}=0.14\right.$ vs $r^{2}=0.01$ in OLS). Built-up area, built-up proportion, population density and access to freshwater availability were stronger determiners of whether or not social distancing will be practically achievable in Upper west region's urban space. In terms of model performance, the GWR performed better than the global model as AICc greatly reduced in GWR (Figure 6).

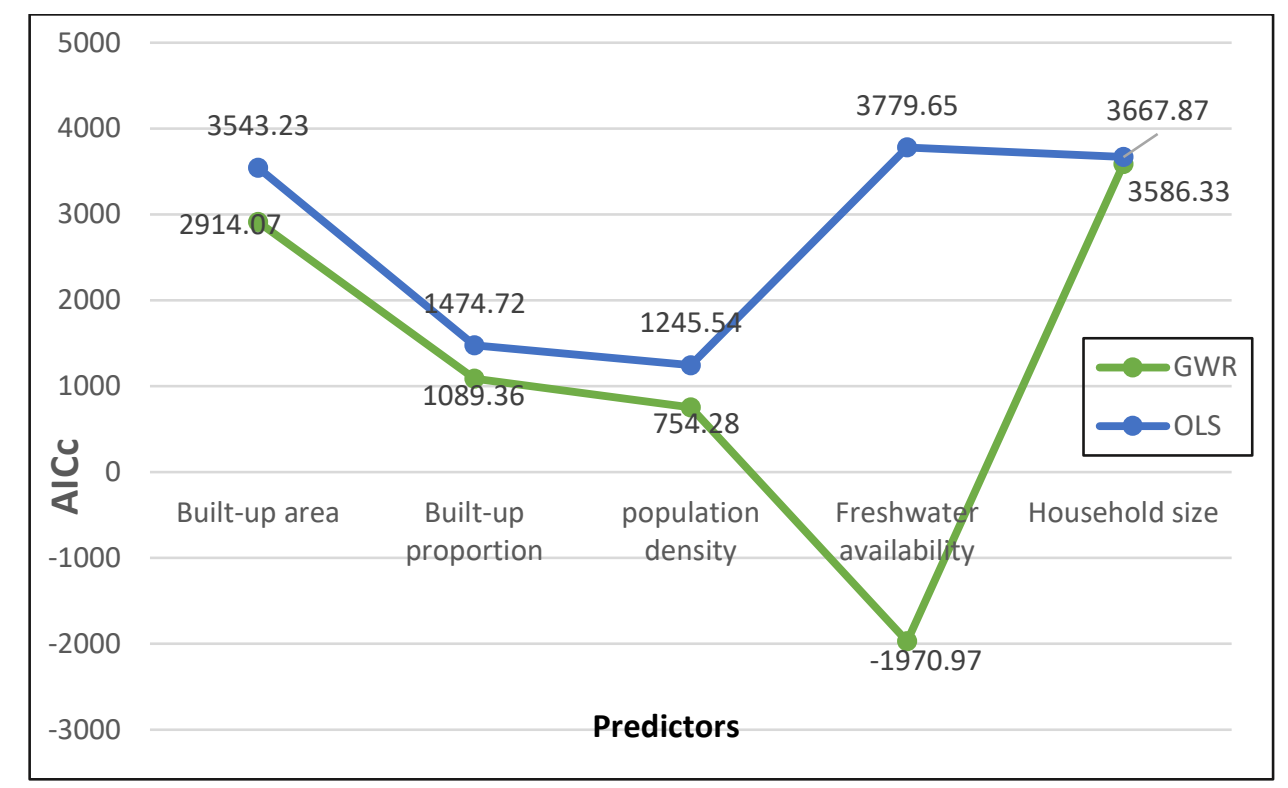

Figure 6: The performance level between ordinary least squares (OLS) and geographically weighted regression (GWR) based on corrected akaike information criterion (AICc).

For example the AICc for built-up area reduced (from 3,543.23 to 2914.07), built-up proportion (from 1,474.72 to 1089.36), population density (from 1245.54 to 754.28 ), and freshwater availability (from 3779.65 to -1970.97 ) and household size (from 3667.87 to 3586.33). Visually analysing the spatially varying relationships between ESDI and the predictors, we established that central part of the urban space depicted stronger association. 
For the association between built-up proportion and ESDI, very strong association class $\left(\mathrm{r}^{2}=\right.$ 0.86 to 0.93 ) was found within the central part of the urban space particularly in towns like Dobile, Zongo, Zingu, Tendamba, Dondoli and Kpaguri. High relationship class $\left(\mathrm{r}^{2}=0.75\right.$ to 0.86) was observed in a concentric ring pattern around the urban core in towns like Mangu, Wa-Sombo and Konta (Figure 7). Areas like Loho lies in between the low and moderate relationships class (moderate, $\mathrm{r}^{2}=0.61$ to 0.75 and low, $\mathrm{r}^{2}=0.41$ to 0.61 ). Most part of the urban spaces, quite farther away from the urban core had very weak relationship between built-up proportion and ESDI $\left(\mathrm{r}^{2}=0.11\right.$ to 0.41$)$ (Figure 7$)$. For the association between ESDI and built-up area $\left(\mathrm{m}^{2}\right)$, we found an eastward shift in the very strong association between the variables (Figure 7), for example very high association class $\left(\mathrm{r}^{2}=0.20\right.$ to 0.32 ) was found in Konta, Napula-Bakule and Beali which are slightly shifted eastward from the urban core. High relationship class $\left(\mathrm{r}^{2}=0.13\right.$ to 0.20$)$ was found in areas like Dunkwa, Danku (eastward), Kpaguri, Kpongu and Boli. Moderate relationship $\left(r^{2}=0.08\right.$ to 0.13$)$ followed a strip-shaped pattern extending from south-eastern part to the central portion of the urban space.

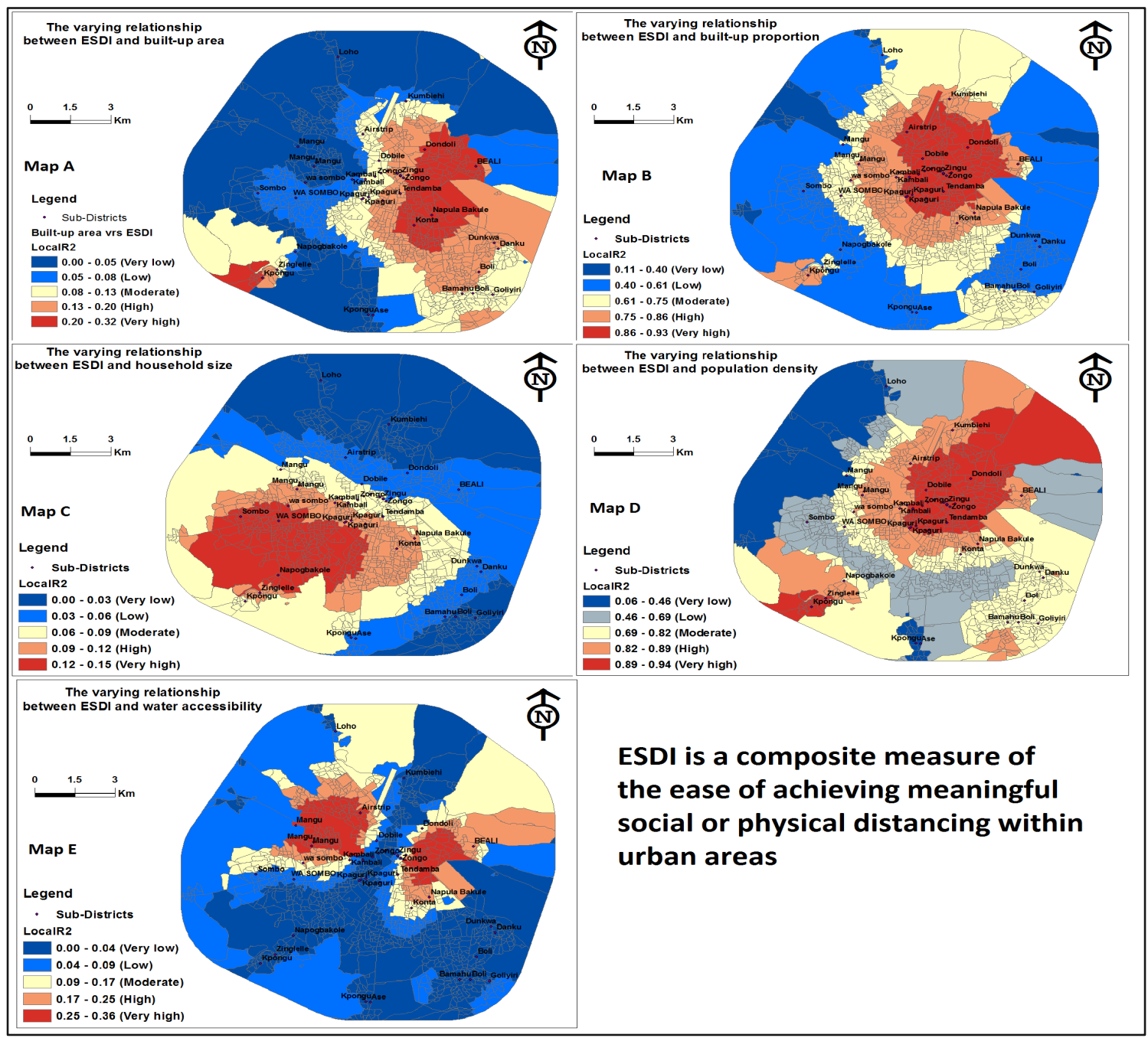

Figure 7: Local relationships between ESDI and built-up area (map A), built-up proportion (map B), household size (map C), population density (map D), and water availability (map E). 
Low to very low association class $\left(\mathrm{r}^{2}=0.00\right.$ to 0.08$)$ dominated the urban area extending predominantly from the central part to the western and northern parts of the area comprising towns such as Loho, Wa-Sombo, Mangu and Kponguase. In these areas, built-up area doesn't determine whether or not social distancing will be achievable. We further investigated how population density determines social distancing and how such relationships vary from one place to the other. Our results show that very strong relationships $\left(r^{2}=0.84\right.$ to 0.94$)$ extends from the central part of the urban space to north-eastern part including towns such as Dondoli, Dobile, Wa Zongo, Zingu, Tendamba and Kpaguri. High relationship group $\left(\mathrm{r}^{2}=\right.$ 0.82 to 0.87 ) was observed in a concentric ring pattern around the urban core comprising towns; Beali, Mangu and Wa-Sombo. Moderate relationship group $\left(r^{2}=0.69\right.$ to 0.82$)$ was observed in a similar concentric ring around places with high relationship class, and in the south-eastern part in towns like Dunkwa, Danku, Boli, Goliyiri and Bahamu. Low to very low association was observed in patched patterns; including areas in the western part, northwestern and part of the eastern flank. With respect to the association between ESDI and freshwater availability, we found only smaller patches displaying relatively strong relationships. For example strong to very strong relationship classes very high $\left(\mathrm{r}^{2}=0.25\right.$ to $0.36)$ and high $\left(r^{2}=0.17\right.$ to 0.25$)$ association classes were found in two patches; eastern and western flanks, comprising towns Tendamba, Mangu, Beali and Zongo. Moderate association between ESDI and water availability was observed in the northern tip and north-eastern parts which lies within Loho community. Low to very low association were observed in major areas within the urban space where water availability does not - even at a moderate level, predict whether social distancing can be achieved or not. Lastly, we investigated the impact of average household size on the ease of achieving social distancing within Upper west urban space. Result indicates that the association - overall, it's relatively weak $\left(r^{2}=0.14\right)$ as compared to other associations. The very high association class $\left(\mathrm{r}^{2}=0.12\right.$ to 0.15$)$ is found within the southern and south-western parts of the urban areas. High association group $\left(\mathrm{r}^{2}=\right.$ 0.09 to 0.12 ) is found in concentric pattern around areas of very high relationships. Moderate relationship $\left(\mathrm{r}^{2}=0.06-0.09\right)$ was also found in a concentric ring around areas of high

relationship and low to very low relationship class (low, $\mathrm{r}^{2}=0.03$ to 0.06 ; very low, $\mathrm{r}^{2}=0.00$ to 0.03 ) dominated the area, typically observed further away from the urban core.

\subsection{Discussion}

The effectiveness and practicality of implementing social distancing is a function of multiple factors which may encompass; the nature of the urban morphology, population density, household size and availability of essential economic and social services (Mansour, 2020; Durizzo et al., 2021). In this study, we mapped the hotspot centres (and assessed autocorrelations) within UWR urban space. We also used geostatistical models to examine the determinants of the ease of achieving effective SD. We presumed that, places with higher proportion of buildings, higher population density and greater built-up footprint area will increase the propensity of social interaction and physical contact (which is a podium for the virus transmission). We also presumed that, since water is inevitable consumable, places with less freshwater supply, the probability of people queuing for public water accessibility will be higher, and will therefore increase physical contact and social interaction. The integrated effects of these factors were presumed to determine whether physical distancing will be practicable or not. Our hotspots analysis reveal that, the ease of achieving social distancing was significantly spatially auto-correlated with hotspots occurring at the centre of the urban 
area (representing 16 the urban core). We also found that population density, built-up proportion/area were all concentrated within the urban core, and diminished with distance from the core -also suggesting significant spatial autocorrelation. Typically, there are intense socio-economic activities within the urban core. Therefore, more structures like shops and houses are developed closer to the core. Also, social interactions resulting from exchanging of goods and services is higher at the urban core. Which may account for higher population and built-up density observed in our study. This is in agreement with a recent study conducted by Mansour (2020) on socio-demographic predictors of covid-19 infection rate across India, where it was found that population density for instance diminished with distance from the urban core, and thus influenced the distribution of the infection -in spatially autocorrelated manner. Our study suggests that, all the areas where high ESDI values concentrated should be targeted, and alternative measures such as encouraging sanitization, wearing suitable nose and facial mask, washing of hands, and limiting spatial mobility be proposed for the people. In the global model, we found that the relationships between ESDI and built-up area, built-up proportion, population density and freshwater availability were statistically significant but not household size. Using the local model which assumes spatially varying relationships, improved estimates for built-up proportion, population density, availability of freshwater and household size were found. This indicates that, built-up area, built-up proportion, population density and access to freshwater availability are stronger determinants of whether or not social distancing will be practically achievable in UWR urban space. This is reasonable because an integrated effect of these factors tend to increase social interaction and personal contact frequency which makes social distancing difficult (Mansour, 2020; Durizzo et al., 2021).

So, these variables should be targeted for adjusting the social distancing protocols within the region urban area. What is obvious here is, that the population density, total builtup area and freshwater availability, regardless of the type of model used, determined significantly the ease of achieving social distancing. This has been discovered in other studies. For example Sigler et al. (2020) and Sirkeci and Yucesahin (2020) found that overcrowding and higher population density and were responsible for faster covid-19 transmission due to difficulty in achieving meaningful social distancing. Our study also found that, freshwater availability was a moderate predictor of the ease of achieving social distancing. This maybe as a result of many people queuing for water at fewer public water pipes/tabs, and in such instances, physical contact will be inevitably higher, thus making social distancing practically difficult. This finding corroborates other studies (Durizzo et al., 2021) about how public or social services availability and infrastructure inadequacy influenced the effectiveness of social distancing in these times of covid-19 pandemic. For example, a study conducted in Accra and Johannesburg in 2021, involving 1,400 respondents found that though many of the urban poor in Accra and Johannesburg observed appropriate hygienic attitude and the willingness to follow social distancing rules. However, significant number of people - despite the city-wide lockdown in these cities defaulted in abiding by the social distancing rules; approximately $25-30 \%$ of people still reported attending larger social gathering, $10-20 \%$ reported receiving guests at homes and $30-35 \%$ of the people leave their homes more than once per week (Durizzo et al., 2021). Further investigation revealed that their inability to abide by the social distancing rules was related to lack of infrastructure such as basic social services (water and sanitation services), and poverty but not the mere unwillingness of the people to accept the new behavioural change enshrined in social 
distancing guidelines (Durizzo et al., 2021). Our spatial analysis revealed that, places within the eastern part of the urban space had less freshwater availability, which is where we observed significant association between the ease of social distancing and freshwater availability. These areas should therefore be targeted for a modified social distancing protocols that reflect local realities. Our study has implication for improving covid-19 management and transmission reduction policies, not only in upper west region, but in Ghana as a whole.

To the best of our knowledge, this is the first study to investigate and map quantitatively areas where social distancing will be practically difficult to achieve; as well as factors influencing this SD difficulty. The study does not only "zoom in" into local level propensity of transmission based on SD distancing condition, but also will aid to scale-up intervention pathways by targeting areas most susceptible or at greater risk of infection of the virus. Additionally, findings of the study may offer sound and clearer guidelines such as building sub-national or micro-scale plan to fight the covid-19 transmission by considering factors such as population density, built-up proportion, the size of buildings $\left(\mathrm{m}^{2}\right)$ and freshwater availability since these variables significantly predicted whether social distancing will be feasible or not in the urban space of upper west region. Based on model comparison, we found that the local model (GWR) had better performance (with reduced corrected akaike information criterion) than global model (OLS) (high corrected akaike information criterion) (Figure 6 ) suggesting that, policy makers and epidemiological researchers in Ghana should rely on the local models to unravel dynamics of the virus from micro-ecological perspective.

\section{Limitation of the study}

Our study relied heavily on physical factors. Factors such as nature of social interactions, socioeconomic activities, gender and age of people were not considered as predictors of achieving effective social distancing. We therefore suggest other researchers to target these areas.

\subsection{Conclusion}

This study mapped the hotspot centres and assessed autocorrelations within UWR urban space. We also used geostatistical models to explore the determinants of the ease of achieving effective SD. our hotspots analysis reveal that, the ease of achieving social distancing was significantly spatially auto-correlated with hotspots occurring at the centre of the urban area (representing the urban core). Population density, built-up proportion/area were all concentrated within the urban core, and diminished with distance from the core-also suggesting significant spatial autocorrelation. In the global model, we found that the relationships between ESDI and built-up area, built-up proportion, population density and freshwater availability were statistically significant but not household size. Application of the GWR improved relationship estimate for built-up proportion, population density, availability of freshwater and household size. This indicates that, built-up area, built-up proportion, population density and access to freshwater availability are stronger determiners of whether or not social distancing will be practically achievable in Upper west region's urban space. We suggest that areas where it is difficult to achieve social distancing due to built-up design or population density, constant surveillance should be adopted for timely detection of the infected. For places where water availability predicted ESDI, we suggest the improvement in water and sanitation facilities to limit clustering of people. 


\section{Data availability:}

All data used in implementing the work can extracted from the links Supplied below;

Fresh water availability: https://sedac.ciesin.columbia.edu/data/set/sdei-trendsfreshwateravailability- grace/data-download

Ease of Social Distancing Index: release@worl dpop.org. Also see [Chamberlain, H.R., Lazar, A.N. and Tatem, A.J. 2021. Ease of Social Distancing Index, mapped for urban areas in sub-Saharan Africa, version 1.0. WorldPop, University of Southampton]. doi:10.5258/SOTON/WP00711

Household size: District Health Information Management System (DHIMS-2 database) (Upon request)

\section{Statements and Declarations}

Authors declare that there is no conflict of interest, and all authors have approved of the publication of the manuscript.

\section{Reference}

Affran, H., Id, B., Addo-lartey, A., Id, J. M. K. A., Id, K. G., Sarfo, B., \& Aryeetey, R. (2020). Limiting spread of COVID-19 in Ghana: Compliance audit of selected transportation stations in the Greater Accra region of Ghana. 1-13. https://doi.org/10.1371/journal.pone.0238971

Adebimpe, W. O. (2015). Community awareness and perception towards rodent control: Implications for prevention and control of lassa fever in urban slums of South-wetsern Nigeria.

Adelekan, I. O. (2010). Vulnerability of poor urban coastal communities to flooding in Lagos, Nigeria. Environment and Urbanization, 22(2), 433-450.

Akyereko, E., Ameme, D., Nyarko, K. M., Sackey, F. A. S., Wuni, B., \& Kenu, E. (2020). Geospatial clustering of meningitis : an early warning system (hotspot) for potential meningitis outbreak in upper east region of Ghana. 54(2).

Amewu, S., Asante, S., Pauw, K., \& Thurlow, J. (2020). The Economic Costs of COVID-19 in Sub-Saharan Africa: Insights from a Simulation Exercise for Ghana. European Journal of Development Research, 32(5), 1353-1378. https://doi.org/10.1057/s41287020-00332-6

Allen, A., Davila, J. D., \& Hofmann, P. (2006). The peri-urban water poor: Citizens or consumers? Environment and Urbanization, 18(2), 333-351.

Asante, D., Twumasi, M. A., Sakyi, A. S. K., Gyamerah, S., \& Asante, B. (2021). A sociogeographic perspective of health and economic impacts of COVID-19 on poor households in ghana. GeoJournal, 2. https://doi.org/10.1007/s10708-021-10487-2

Asante, L. A., \& Mills, R. O. (2020). Exploring the Socio-Economic Impact of COVID-19 Pandemic in Marketplaces in Urban Ghana. Africa Spectrum, 55(2), 170-181. https://doi.org/10.1177/0002039720943612 
Baada, J. N., Antabe, R., \& Sano, Y. (2021). Differentiated agrarian vulnerabilities and generalized national responses to COVID-19 in the Upper West Region of Ghana. Journal of Agrarian Change, 21(3), 604-619. https://doi.org/10.1111/joac.12434

Braimah, I., \& Filmua, N. (2011). Community ownership and management of water and sanitation facilities: issues and prospects in the Nadowli district of the upper west region of Ghana. Journal of Sustainable Development in Africa, 13(3), 74-87.

Baca Campodonico, J. F., Peschiera Cassinelli, J., \& Mesones, J. (2014). The impact of public expenditures in education, health, and infrastructure on economic growth and income distribution in Peru. Health, and Infrastructure on Economic Growth and Income Distribution in Peru (February 14, 2014).

Baker, J. L. (Ed.). (2012). Climate change, disaster risk, and the urban poor: Cities building resilience for a changing world. The World Bank.

Caley, P., Philp, D. J., \& McCracken, K. (2008). Quantifying social distancing arising from pandemic influenza. Journal of The Royal Society Interface, 5(23), 631-639.

Delhi, N. N. (2003). National sample survey organisation; 2002. National sample survey organisation. Disabled persons in India. NSS Report, 485.

Durizzo, K., Asiedu, E., Van der Merwe, A., Van Niekerk, A., \& Günther, I. (2021). Managing the COVID-19 pandemic in poor urban neighborhoods: The case of Accra and Johannesburg. World Development, 137, 105175. https://doi.org/10.1016/j.worlddev.2020.105175

Ferguson, N. M., Ainslie, K. E. C., Walters, C. E., Fu, H., Bhatia, S., Wang, H., Xi, X., Baguelin, M., Bhatt, S., Boonyasiri, A., Boyd, O., Cattarino, L., Ciavarella, C., Cucunuba, Z., Cuomo-Dannenburg, G., Dighe, A., Dorigatti, I., van Elsland, S. L., FitzJohn, R., ... Riley, S. (2020). Evidence of initial success for China exiting COVID19 social distancing policy after achieving containment. Wellcome Open Research, 5, 114. https://doi.org/10.12688/wellcomeopenres. 15843.1

Ferguson, N. M., Cummings, D. A., Cauchemez, S., Fraser, C., Riley, S., Meeyai, A., et al. (2005). Strategies for containing an emerging influenza pandemic in Southeast Asia. Nature, 437(7056), 209-214.

Fielmua, N., Akudugu, M. A., \& Dugle, G. (2019). Water, sanitation and rural livelihoods nexus: an exploratory study of Wogu in the Upper West Region of Ghana. Ghana Journal of Development Studies, 16(2), 199-219.

Katey, D., Morgan, A. K., Asori, M., Ampofo, S. T., \& Mpobi, R. K. J. (2021). COVID-19 and the marginalized: an opinion piece on further measures to address COVID-19 in prisons in Sub-Saharan Africa. International Journal of Prisoner Health, June. https://doi.org/10.1108/IJPH-12-2020-0101

Mansour, S., Al, A., Al-said, A., \& Al-said, A. (2020). Sociodemographic determinants of COVID-19 incidence rates in Oman: Geospatial modelling using multiscale geographically weighted regression (MGWR) Sustainable Cities and Society 65 (2021) 102627/ https://doi.org/10.1016/j.scs.2020.102627

Kimani-Murage, E. W., \& Ngindu, A. M. (2007). Quality of water the slum dwellers use: The case of a Kenyan slum. Journal of Urban Health, 84(6), 829-838.

Lewnard, J. A., \& Lo, N. C. (2020). Scientific and ethical basis for social-distancing 
interventions against COVID-19. The Lancet Infectious Diseases.

Lloyd-Jones, T., \& Rakodi, C. (2014). Urban livelihoods: A people-centred approach to reducing poverty. Routledge.

Morgan, A. K. (2020). Making COVID-19 prevention etiquette of social distancing a reality for the homeless and slum dwellers in Ghana: lessons for consideration. Local Environment, 536-539. https://doi.org/10.1080/13549839.2020.1789854

Oppong, J. R., Mayer, J., \& Oren, E. (2015). The global health threat of african urban slums: The example of urban tuberculosis. African Geographical Review, 34(2) 182-195.

Park, S. W., Sun, K., Viboud, C., Grenfell, B. T., \& Dushoff, J. (2020). Potential roles of social distancing in mitigating the spread of coronavirus disease 2019 (COVID-19) in South Korea. medRxiv.

Padoch, C., Brondizio, E., Costa, S., Pinedo-Vasquez, M., Sears, R. R., \& Siqueira, A. (2008). Urban forest and rural cities: Multi-sited households, consumption patterns, and forest resources in amazonia. Ecology and Society, 13(2).

Pfattheicher, S., Nockur, L., B€ohm, R., Sassenrath, C., \& Petersen, M. B. (2020). The emotional path to action: Empathy promotes physical distancing during the COVID-19 pandemic.

Prem, K., Liu, Y., Russell, T. W., Kucharski, A. J., Eggo, R. M., Davies, N., et al. (2020). The effect of control strategies to reduce social mixing on outcomes of the COVID-19 epidemic in wuhan, China: A modelling study. The Lancet Public Health.

Nuoh, R. D., Nyarko, K. M., Nortey, P., Sackey, S. O., Lwanga, N. C., Am, D. K., Nuolabong, C., Abdulai, M., Wurapa, F., \& Afari, E. (2016). Supplement article Review of meningitis surveillance data, upper West Region, Ghana 2009-2013. 25(Supp 1), 15. https://doi.org/10.11604/pamj.supp.2016.25.1.6180

Richardson, D. L., Duncan, M. J., Clarke, N. D., \& Myers, T. D. (2021). The influence of COVID-19 measures in the United Kingdom on physical activity levels, perceived physical function and mood in older adults : A survey-based observational study ABSTRACT. Journal of Sports Sciences, 39(8), 887-899. https://doi.org/10.1080/02640414.2020.1850984

Reluga, T. C. (2010). Game theory of social distancing in response to an epidemic. PLoS Computational Biology, 6(5).

Sen, A. (1992). Inequality Re-examined. Russell Sage Foundation and Clarendon Press.

Tsai, P.-J., Lin, M.-L., Chu, C.-M., \& Perng, C.-H. (2009). Spatial autocorrelation analysis of health care hotspots in Taiwan in 2006. BMC Public Health. https://doi.org/10.1186/1471-2458-9-464.

Upoalkpajor, J.-L. N., \& Upoalkpajor, C. B. (2020). The Impact of COVID-19 on Education in Ghana. Asian Journal of Education and Social Studies, 9(1), 23-33. https://doi.org/10.9734/ajess/2020/v9i130238

Yeboah, A. S., Takyi, S. A., Amponsah, O., \& Anaafo, D. (2020). Assessing the practicality of the COVID-19 social distancing guidelines to the urban poor in the Ghanaian context. Social Sciences \& Humanities Open, 2(1), 100087. https://doi.org/10.1016/j.ssaho.2020.100087 
